\title{
P04-1-8 Poster session
}

\section{Effects of angiotensin II on excitatory synaptic transmission in rat nucleus tractus solitarius neurons}

\author{
Yoshiaki Ohi, Misaki Tanimoto, Daisuke Kodama, Akira Haji \\ Laboratory of Neuropharmacology, School of Pharmacy, Aichi Gakuin University, Japan
}

Baro- and chemoreceptor afferents project to the nucleus tractus solitarius (NTS) neurons and these signal transmission play an important step in cardiorespiratory control. The expression of angiotensin II type $1\left(\mathrm{AT}_{1}\right)$ and $2\left(\mathrm{AT}_{2}\right)$ receptors is confirmed in the NTS. Activation of $\mathrm{AT}_{1}$ receptors is demonstrated to activate endotherial nitric oxide synthase and produced NO stimulates voltage-dependent $\mathrm{Ca}^{2+}$ currents (Cheng et.al., 2012, Li et.al., 2014). On the other hand, there is a report that $\mathrm{AT}_{1}$ receptors inhibit nitric oxide synthesis by NADPH oxidase (Wang et.al., 2006). Therefore the physiological roles of angiotensin II in the NTS are controversial. In this report, we aimed to reveal the effects of angiotensin II on the excitatory synaptic transmission in the rat NTS neurons by using a slice patch-clamp technique.

Superfusion of angiotensin II $(1 \mu \mathrm{M})$ increased the frequency of spontaneous excitatory postsynaptic currents (sEPSCs) in $33 \%(6 / 18)$ of neurons and decreased it in $39 \%(7 / 18)$ of neurons without any significant effect on the amplitude. It had no effect in the remaining $28 \%$ (5/18) neurons. The prior application of $\mathrm{AT}_{1}$ receptor antagonist losartan $(10 \mu \mathrm{M})$ blocked the increase in the sEPSCs frequency induced by angiotensin II and that of $\mathrm{AT}_{2}$ receptor antagonist PD-123319 $(30 \mu \mathrm{M})$ blocked the decrease in the sEPSCs frequency. The angiotensin II-induced increase in the sEPSCs frequency was also blocked by prior application of L-NAME $(100 \mu \mathrm{M})$.

The present study demonstrates that angiotensin II (1) facilitates glutamate release from the presynaptic terminals by production of NO through $\mathrm{AT}_{1}$ receptors in some class of NTS neurons, and (2) inhibits glutamate release from the presynaptic terminal via $\mathrm{AT}_{2}$ receptors in other class of neurons. These results suggest that angiotensin II modulates baro and chemoreceptor reflex through $\mathrm{AT}_{1}$ and $\mathrm{AT}_{2}$ receptor activation in the NTS. 